\title{
As tramas da socialização: uma análise socioantropológica sobre sexualidade juvenil na religião
}

Elias Evangelista Gomes

Elias Evangelista Gomes é antropólogo (UFMG), mestre e doutorando em Sociologia da Educação (USP) e investigador do Grupo de Pesquisa sobre Práticas de Socialização Contemporâneas da Universidade de São Paulo (GPS-USP). Este estudo foi financiado pela Fundação de Amparo à Pesquisa do Estado de São Paulo (FAPESP).
Resumo: 0 artigo procura contribuir para a reflexão sobre a diversidade e unidade de posicionamentos sobre educação e sexualidade no interior de um grupo pertencente ao campo evangélico brasileiro. Resulta de uma etnografia realizada junto a uma igreja evangélica neopentecostal. Investigaramse os modos como a igreja e os sujeitos (adultos e jovens) constroem os processos de diálogo, negociação e controle na esfera da sexualidade. Sob a ótica da Sociologia da Educação, realizou-se uma análise dos argumentos e contraargumentos, estratégias e cosmologias relacionados às adesões e dissidências sexuais. Conclui-se que os jovens vivenciam a socialização para a sexualidade entre práticas de adesão e dissidência e que a tentativa da igreja de controlar os jovens, por meio de orientadores cuja estratégia é não ultrapassar o limite do que seus discípulos suportariam, pode ser abalada pelo fato de que, por outro lado,esses jovens apenas falam, para seus orientadores, sobre aquilo que não causa tensão em demasia.

Palavras-chaves: Socialização. Religião. Sexualidade. Juventude. 
INTRODUÇÃO

Este artigo é resultado de uma etnografia realizada durante dois anos, na Comunidade Evangélica Sara Nossa Terra, da vertente neopentecostal, localizada na Rua Augusta, em um eixo cultural e econômico importante da cidade de São Paulo. ${ }^{1}$ Por meio de festas, atividades lúdicas, eclesiais e valores próximos das camadas médias, atrai jovens de vários seguimentos sociais, especialmente, aqueles da periferia paulistana identificados com esses valores.

Neste artigo, pretende-se descrever parte das estratégias de socialização para a sexualidade utilizadas no contexto da igreja. Elas implicam o diálogo, a negociação e o testemunho, visando ao controle da sexualidade juvenil. ${ }^{2}$

A partir da ótica da Sociologia da Educação, busca-se contribuir para a área de pesquisa acerca das estratégias de socialização difusa, aquelas que não acontecem especialmente no âmbito da escola, mas que estão relacionadas sobretudo a outras intâncias sociais que incidem sobre os sujeitos com perspectivas formativas, ora com estratégias semelhantes às escolares ora com estratégias distintas e conteúdos particulares.

Para as áreas da antropologia e da sociologia, a religião sempre apresentouse como objeto de análises introdutórias para o entendimento das sociedades. No Brasil, tal questão não se revela menos importante. Analisar os processos educativos no âmbito da religião contribui para refletirmos sobre a formação de um contingente muito significativo de pessoas no nosso país. A religiosidade e as pessoas religiosas estão presentes na escola e, por isso, compreender os sujeitos e seus processos educacionais não escolares pode contribuir para melhor entendermos os conflitos e práticas culturais que chegam ao ambiente escolar.

A partir de uma inspiração maussiana, a educação/estratégia socializadora para a sexualidade na igreja evangélica pode ser analisada com base na noção

1 O neopentecostalismo é uma vertente das igrejas evangélicas, fortemente caracterizado pelo uso das mídias (TV, rádio, jornais e internet) para difusão da fé e estratégias de psicologização da mensagem cristã (GOMES, 2010).

2 Para efeitos de orientação da leitura, cabe informar que a coleta de dados, por meio de entrevistas e de observação, foi realizada com jovens entre 18 e 25 anos, faixa etária média dos jovens frequentadores da igreja. Foram entrevistados ainda três casais de pastores, um casal de bispos, bem como parentes, irmãos, mães e pais. Os resultados analisados vão além das entrevistas, levando em consideração o trabalho etnográfico de dois anos realizado na igreja observando ocasiões diversas de culto e lazer. 
de socialização como fato social total: um fenômeno geral e generalizado, realizado pela co-participação, ainda que tensa, de instâncias sociais e sujeitos, exprimindo-se nas dimensões "econômica (origem social), política (posição ideológica), religiosa (crença) e estética (gosto)” (SETTON, 2009, p. 43). Concebe-se o social de modo dialético, sem privilegiar de antemão sujeitos ou instâncias, que podem ser observados como duas totalidades conectadas em contextos histórica e socialmente definidos.

Vista assim, a socialização é um processo social composto por reciprocidades de símbolos (princípios), cravadas profundamente no sujeito e em suas disposições de cultura. Essa acepção conceitual permite compreender os aspectos simbólicos das trocas recíprocas como eixo fundamental das relações sociais entre pessoas morais, o que permite compreender a relação entre os distintos projetos das instâncias e dos sujeitos da socialização. Segundo Claude Levi-Strauss (2003), a noção de fato social permite entender, simultaneamente, o social e o individual, o físico e o psíquico.

Assim, as práticas de socialização para a sexualidade na juventude entre evangélicos possui certo sentido social, pois somente pode ser compreendida sob a forma de fato social, visto que os princípios das práticas possuem natureza diversa e podem adquirir uma significação global, tornando-se uma totalidade (LEVI-STRAUSS, 2003). A socialização dos jovens evangélicos se complexifica num cenário de reconfiguração das práticas de socialização (SETTON, 2002), pois forma-se circuito de cuidado composto por diferentes repertórios culturais (GARCÍA-CANCLINI, 2008) que possibilitam aos sujeitos construirem redes de interações tensas e de parceria, elaborar seus argumentos, visões de mundo e leituras sobre suas experiências sociais.

\section{A cosmologia eVANGÉlica PARA A SEXUALIDAdE}

A seguir, serão descritas três estratégias presentes no processo de socialização da sexualidade na igreja evangélica. Entretanto, é oportuno ressaltar que há um padrão legítimo balizador do agendamento da sexualidade juvenil na igreja: "sexo apenas com o cônjuge, sendo ele do sexo oposto". Sabe-se que elas não são exclusivas dos jovens, mas, tendo em vista a priorização do tema nessa etapa da vida, elas se tornam mais utilizadas no caso deles.

Da série de estratégias eclesiais na socialização para a sexualidade de jovens, a primeira tem como ponto de partida a mensagem bíblica. Ela se baseia na delimitação do que seja "viver no espírito" e "viver na carne". 
$\mathrm{Na}$ igreja evangélica, há uma polarização entre santo e mundano, sagrado e profano, celestial e terreno, carne e espírito. Na perspectiva nativa, o espiritual é simbolizado pelas relações entre sujeito e Sagrado. Assim, as percepções e emoções humanas devem estar sensíveis às experiências tanto "sobrenaturais", como àquelas vividas a partir da adesão "completa" aos princípios de fé legitimados pela igreja, que interpreta e legitima o conteúdo bíblico. O carnal pode ser tudo aquilo que não é espiritual ou qualquer dissidência em relação ao que o é, sendo percebido com muito mais intensidade nas dimensões das experiências corpóreas.

A expressão de uma vida bem sucedida na esfera afetiva-sexual resulta da vitória do espírito sobre a carne, da santidade sobre o pecado. Como tratado anteriormente, dentre as estratégias mais amplas da igreja pesquisada está a oferta de um discurso de sucesso em todas as esferas da vida. Assim, viver plenamente no marco regulatório proposto, do agendamento da sexualidade é uma das provas de sucesso espiritual.

Busca-se definir o que é vida espiritual e carnal; ainda que de forma implícita e não oficial, a igreja classifica pecados e os hierarquiza em função de algum grau de gravidade. A existência de hierarquização de pecados é negada pelos evangélicos, porém ela é observável a partir da noção implícita do que se entende por "consequências ruins" das dissidências, bem como a partir dos constrangimentos sociais decorrentes delas. Essa percepção classificatória nada mais é do que a soma tensa de percepções acerca da fé, preservadas durante séculos a partir da literatura bíblica, com valores culturais disponíveis na sociedade ocidental e influenciada pelos valores cristãos. Pode-se dizer, pois, que a igreja agrega novas significações sobre a sexualidade para dar novo design ao seu programa de socialização.

Segundo os preceitos da igreja, os evangélicos têm ou deveriam ter ciência de que todos estão sujeitos ao pecado, à carne e ao erro. Assim, a instituição desenvolve uma segunda estratégia que objetiva levar as pessoas a reconhecerem que estão sujeitas ao pecado e que aqueles que pecaram necessitam se arrepender e receber o perdão. A igreja, com isso, busca levar o sujeito a ter conhecimento do que é errado e pecado, bem como estimula o reconhecimento das situações de erro. São medidas importantes para a reconciliação do jovem consigo, com Deus e com a igreja.

É recorrente ouvir nos cultos e falas de pastores e jovens que é importante não reincidir no erro; primeiro, porque isso constantemente colocará o sujeito em situação de desvio, segundo, porque o pedido de perdão se tornará apenas 
um ritual: "pecou, vai lá e pede perdão”. Essa crítica é desenvolvida por vários jovens e pelos pastores e líderes, que consideram que “o melhor é não pecar" . O sentimento com que o jovem fica é o de que se afastou de Deus, ou seja, se afastou do que havia de melhor na experiência humana (o contato com Deus), recaindo sobre si um sentimento de tristeza.

Uma importante ilustração feita pelos “mensageiros da palavra do Senhor" durante os cultos e discipulados é que Deus está com as mãos estendidas e que o sujeito pode estar embaixo da mão dele, ou sob a benção dele. Quando a pessoa não está sob a mão (ou benção), não é que Deus tenha se reposicionado em retaliação ou por qualquer outro motivo, mas porque a própria pessoa se deslocou, afastando-se ou se desviando. Essa noção se refere à imagem de que "Jesus Cristo é o mesmo ontem, hoje e será eternamente", conforme registro bíblico em Hebreus, capítulo 13 e versículo 8 (BÍBLIA ONLINE).

Nesse sentido, “pedir perdão" entra no circuito de socialização da igreja como objetivo de recompor o circuito de dádivas (MAUSS, 2003). O funcionamento do sistema de trocas acontece da seguinte maneira: "Deus deu seu único filho para morrer na cruz e assim perdoar os pecados de todos nós". Por essa razão, o cristão deve receber a salvação (“vida eterna”) e deve retribuir o "desprendimento" do Sagrado em "dar gratuitamente seu filho amado em sacrifício no lugar de nós", com uma vida de santidade. Nessa perspectiva, o pecado rompe o circuito de trocas como uma não-retribuição ou uma retribuição que soa inadequada. "Pedir perdão" objetiva, assim, recompor o circuito de dádivas, iniciando um novo processo em que o fiel oferece seu arrependimento, "humilha-se diante do Senhor", a fim de receber o perdão e retribuir com a manutenção de uma vida em santidade e a adoração ao Sagrado.

Enfim, o que é mais importante nesse sistema não são exatamente as trocas em si, mas o vínculo social estabelecido entre fiel e Sagrado; consequentemente, o vínculo com a comunidade de fé, a "representante de Deus na terra”. Nesse circuito, confirma-se a posição dos sujeitos na estrutura, a partir do que podem e devem dar, receber e retribuir, de modo que essa estratégia de convidar as pessoas a pedirem perdão visa levar o fiel a não "recusar a aliança e a comunhão" (MAUSS, 2003, p. 202) e a manter a relação entre os sujeitos da socialização em equilíbrio, aspectos fundamentais para a continuidade do processo socializador na igreja.

A terceira estratégia de socialização para a sexualidade observada na igreja

Líder é um sujeito que coordena trabalhos e atividades eclesiais e lúdicas na igreja. Há líderes adultos e líderes jovens. Ambos atuam na formação e socialização de jovens. 
é uma modalidade de retribuição. O sujeito é convidado a testemunhar para a comunidade de fiéis a superação do pecado, da crise ou um problema em qualquer espaço da vida. Contudo, a prática de testemunho tem como função não apenas confirmar o prestígio de Deus na resolução do problema, mas evidenciar a capacidade do sujeito de criar condições para a superação de seus problemas.

O sujeito cede às renúncias e aos sacrifícios programados para sua socialização visando receber em troca testemunhos de reconhecimento, consideração e admiração. Essa troca é carregada de afetividade; o sujeito que testemunha uma "vitória" para a igreja, por mais que negue o propósito, tenta receber o reconhecimento da comunidade e torna-se referência de conduta para os demais.

Além disso, na igreja evangélica, o testemunho - ação de publicizar alguma mudança positiva na vida - é usado como estratégia de socialização que visa fazer os demais fiéis acreditarem na possibilidade de vitória sobre as tensões da vida cotidiana a partir da adesão ao programa institucional da igreja. Nesse sentido, o testemunho funciona como uma baliza para as experiências sociais e visa orientar as experiências de cada sujeito e do grupo para que sejam bem sucedidos nos termos dessa fé.

\section{AS COMPREENSÕES SOBRE SEXUALIDADE}

As principais dissidências afetivo-sexuais observadas na igreja que geram maiores rumores e impactos são: relação sexual antes do casamento e relação sexual com pessoas do mesmo sexo, pois elas parecem ferir os pilares dos ensinamentos eclesiais. Percebe-se que os jovens da igreja, majoritariamente, vivenciam uma negação inicial em relação às dissidências afetivo-sexuais, diante da qual uns persistem mais e outros menos. No caso daqueles de gosto afetivo-sexual de sexo oposto, considera-se passar por um risco de dissidência aqueles que demoram para transformar o namoro ou noivado em casamento ${ }^{4}$. No caso dos jovens que gostam de pessoas do mesmo sexo, a noção de que é uma pulsão inexplicável está mais presente do que nos outros casos. Todos os sujeitos pesquisados (jovens e adultos) apresentam a noção de que o sexo é algo “quase incontrolável”, inato do ser humano.

Segundo um líder, "as pessoas foram escolhidas por Deus no ventre de

4 Defino como gosto afetivo-sexual os modos de ser, pensar e agir na esfera da sexualidade, mais precisamente, refiro-me às categorias de pensamento, julgamento e classificação sobre a sexualidade (GOMES, 2010). 
suas mães, mas o meio pode condicionar a pessoa para uma vida correta ou não”. Entende-se que as pessoas nasçam "puras” e sejam determinadas pela cultura, pelas condições sociais nas quais foram socializadas. A partir dessa constatação, a igreja luta para que as disposições de habitus de seus fiéis não sejam resultantes da cultura geral, mas determinadas pela cultura bíblica, denominada de "princípios do Senhor".

Com isso, observa-se uma racionalidade biológica aliada a uma racionalidade cultural, compreendendoo sexo como constitutivo do ser humano e, concomitantemente, afirmando a prática dele como construção social. Ruth Benedict (1972) lembra que a cultura é como uma lente por meio da qual o sujeito enxerga o mundo, cada cultura possuindo uma lente própria. Entende-se, então, porque a igreja luta para que seus princípios sejam os graus dessa lente. Ao ver relevância em si mesma, a igreja entra na disputa pela socialização do sujeito e "não abre mão" de se colocar como matriz de posicionamentos e condutas.

Em outras palavras, a igreja, por considerar os gostos afetivos-sexuais resultados das experiências sociais, e por peceber que são disputados por diferentes instâncias, atua com o objetivo de controlar e compor aquelas disposições tidas como "inatas" e orientar aquelas disposições de habitus que precisam ser manifestadas como um estilo de vida cristão. Ainda na aliança entre biológico e cultural, o gosto afetivo-sexual de sexo oposto entra no quadro das normatividades, do natural, do biológico, da pré-determinação sagrada, enquanto o gosto de mesmo sexo (bem como o dissidente temporal) é considerado uma construção social na qual os sujeitos se incorporaram por diferentes razões.

As falas dos sujeitos, especialmente no caso dos pastores e líderes, estão pautadas porcertotipo de psicologização (literaturatécnica) e “sociologização" (explicações da psicologia social conectadas com a sociologia) ou ainda relacionada ao construtivismo social. Em suma, o corpo de pastores tem certo conhecimento de causa para não afirmar que dissidências sexuais são patologias ou determinações meramente espirituais 5 . Esse tipo de postura se relaciona ao tipo de igreja que desejam constituir: moderna; escolarizada e “antenada”com a classe média.

Os jovens entendem que o exercício do sexo ajuda a amenizar tensões e crises de relacionamento entre os parceiros. Porém, consideram que basear a relação afetiva apenas na atividade sexual, no lugar do diálogo interpessoal

Sobre conhecimento perito, Cf. GIDDENS, 1991. 
e com o Sagrado, pode acarretar problemas futuros para o casamento. Essa noção faz parte da argumentação dos socializadores e é compartilhada pelos socializandos; também é homóloga à posição dos pastores e líderes que, no cuidado de adultos, dispensam os mesmos argumentos e, por vezes, identificam o fato de a união ter se iniciado motivada pelo sexo como a causa dos obstáculos enfrentados na relação conjugal futura.

$\mathrm{Na}$ igreja, entre jovens e adultos, considera-se que o namoro é um momento para "conhecer" e "planejar", que o sexo não deve ser a prioridade da relação. Subjetiva-se a noção de namoro como etapa que antecede às demais. Isso faz com que os jovens de gosto afetivo-sexual de sexo oposto se aproximem mais dos princípios da igreja. Aqueles de gosto afetivo-sexual de mesmo sexo costumam não investir no namoro, “por receio de perder tempo", pois, em suas perspectivas futuras, pretendem se relacionar apenas com pessoas do sexo oposto.

Para todos, a dissidência afetivo-sexual é uma pulsão situacional: "Bum! Fui lá e fiz, sem premeditar”; por isso, é necessária a correspondência de perspectivas entre os casais de namorados. Dessa maneira, insiste-se que devam atuar de forma recíproca na ação favorável à santidade (não fazer sexo antes do casamento) e que a reciprocidade seja rompida em caso contrário. Mesmo que tenha ocorrido uma ruptura, ela deve ser tratada como momentânea, devendo os sujeitos rearticular as estratégias para que a reciprocidade referente aos princípios de santidade seja mantida.

\section{MODOS DE CUIDAR}

Os pastores e jovens da igreja sabem da existência de dissidências sexuais entre o fiéis, contudo, a estratégia eclesial, compartilhada por pastores, líderes adultos e jovens, é não dizer de imediato aos novos convertidos e visitantes o que "não é permitido" e definido como "carne”, na polarização cosmológica "espírito" e “carne”, referentes ao agendamento da sexualidade. Nesses aspectos, o discipulado coletivo é uma espécie de sociabilidade controlada, repleta de intenção e nada desinteressada (BOURDIEU, 1996). Por meio dele, busca-se estimular a aproximação e a familiarização entre os sujeitos ("tornarem-se amigos") favorecendo a criação de um ambiente de confiança para "consolidar" o jovem dentro da igreja, de modo que ele possa, com o tempo, reconhecer, em si mesmo, aquilo que é pecado, bem como perceber a necessidade de relatar suas experiências dissidentes e receber os cuidados de seus socializadores. 
Ter um grupo de amigos, sentir-se acolhido, ter um lazer na cidade, funcionam como pontos de partida para que o jovem possa se inserir num circuito de cuidado, de trocas simbólicas em torno do ethos privado (DUARTE, 2005). As práticas socializadoras para a adesão ao agendamento da sexualidade preservadas pela igreja se baseiam em processos comunicativos, iniciados no lazer, nas festas e nos cultos e intensificados em um ambiente de confiança, para que os "testemunhos de vitória" dos socializadores e os relatos de experiências dos jovens possam se encontrar.

Em outras palavras, o cuidado (a socialização) para a sexualidade é desenvolvido, majoritariamente, na relação entre líder e discípulo, em um ambiente comunicacional que deve(ria) funcionar, tipicamente, da seguinte forma: o socializador disponibiliza manifestações de carinho e atenção, o jovem recebe essa intenção e retribui com suas experiências dissidentes, aquelas que the incomodam. A partir disso, o jovem é aconselhado a seguir a parte cosmológica do perdão e iniciar uma nova troca simbólica, esta com o Sagrado, que na verdade serve, em grande medida, para atenuar a tensão com a comunidade. Segundo Setton (2009), no processo socializador, essas trocas aproximam os sujeitos como parceiros. Vale dizer, a comunicação entre sujeitos, a intersubjetividade, a sociabilidade entre eles compõem, ainda que de forma tensa, o circuito de dádivas, fundamentais para os propósitos da igreja.

Então, eu disse para ele se afastar daquilo que fazia ele pensar em outro menino, tipo ir às baladas que têm gays, ficar muito tempo na internet, para vir mais na igreja, que as festas da Sara são boas, tem gente bonita, bons DJ's. Disse para ele procurar o pastor que ele ia ajudá-lo. Orar para que a família dele se rendesse aos pés do Senhor, os amigos também. Falei para ele relaxar que Deus ia fazer a obra (a reconversão de gosto) na vida dele. Eu dei vários exemplos meus, do que eu consegui superar, para ele ver que também era possível.

Muitos jovens procuram seus líderes para serem cuidados na adesão ou "reconversão" de seus percursos sexuais. Buscam um argumento convincente, capaz de balizar suas experiências. Os socializadores, por vezes, lançam mão de seus testemunhos de vida, suas superações, nem sempre relacionadas à sexualidade, para comprovar que é possível a adequação e a adesão.

Avalia-se, de forma resumida, que: os jovens, nesse processo comunicacional, refinam suas categorias de julgamento a fim de discenir entre "carne" e "espírito", bom e ruim, Sagrado e profano, adequado e inadequado para suas experiências sociais ${ }^{6}$. 0 evangélico que possui um estilo de vida cristão deve saber classificar as experiências sociais, tal como o gosto (BOURDIEU,

6 Afirmo'refinam', pois essas percepções nem sempre se iniciam nas práticas socializadoras da igreja, mas ao longo da vida. 
2003, 2008), entre bens "vulgares" e bens "distintos", pecado e santidade; prescritivamente, deve saber compor suas experiências a partir da dualidade espírito-santidade.

Nesses termos, o cuidado da sexualidade na igreja evangélica é baseado, sobretudo, na "palavra de Deus", em uma linguagem própria para denominar as convenções institucionalmente formuladas. Sobre esses aspectos, faz sentido a defesa de Peter Berger (1985), segundo o qual toda linguagem empírica constitui um nomos em formação ou uma consequência histórica da ação nomizante ao longo das gerações. Seguindo a definição ofertada por esse autor, a igreja busca construir um ato nomizante original, baseado na Bíblia, na classificação do que é “carne” e “espírito” na esfera sexual.

Como lembra Foucault (1988), a pastoral cristã fez passar pelo crivo da palavra todos os fenômenos relacionados ao sexo. Assim, na igreja evangélica, os jovens têm disponíveis discursos que visam confirmar a possibilidade de adesão. Primeiro, a Bíblia fala a "palavra de Deus" a respeito do sexo; segundo, os sujeitos, por meio de testemunhos, fornecem provas concretas de superação e adesão; terceiro, o discipulado acolhe os jovens a fim de reconhecerem, confessarem e pedirem perdão por seus pecados. Assim, para atrair o jovem ao agendamento da sexualidade, a igreja o acolhe para que ele possa "falar" sobre suas experiências, receber a "palavra do Senhor", reconhecer o pecado, pedir e receber o perdão e seguir em frente, vivenciando plenamente o circuito de cuidado e a "palavra do Senhor".

MEDIAÇÕES NA SOCIALIZAÇÃO

Na realização do trabalho de campo, não foi possível observar atividades específicas de socialização para a sexualidade entre líderes de jovens e jovens líderes com seus respectivos discípulos individuais, uma vez que a igreja aborda o tema em situações individualizadas (ambientes de confiança) para não constranger os fiéis. Porém, líderes e discípulos, em entrevistas e observações realizadas em atividades lúdicas, passeios, festas, cultos, visitas nas casas dos jovens, relataram suas impressões sobre essas situações e como funcionam algumas estratégias de socialização para a sexualidade, que nos leva a uma melhor compreensão sobre o circuito de cuidado nessa esfera da vida. Perguntado sobre qual foi o tema mais complexo que um discípulo trouxe e que não foi possível resolver, um jovem líder respondeu: 
Vários. Então, chegou um menino que estava vivendo alguns conflitos sobre a questão G (Gay). Aí, não sabia bem como lidar com isso. Nunca tinha tido um discípulo com essas questões. Quando ele me procurou, falei para ele: "Vou procurar alguém que possa te ajudar”. Ele continuou sendo meu discípulo, mas não tinha como eu trabalhar isso com ele. A igreja tem psicólogos, pessoas experientes que podem auxiliar essas pessoas. A Sara é uma igreja bem preparada para lidar com isso.

Diante da questão sobre quais são os principais problemas que os jovens trazem, outro jovem líder afirmou:

Eles têm dúvidas de todos os tipos: "quando namorar?”, “quando está gostando de alguém”, "se pode namorar ou não". Eu defini com os meus discípulos que só pode namorar depois dos 18 anos. Pois, aí, se tem mais responsabilidade. Tem que ter responsabilidade, pois namoro é para casar, não é? Quando o problema é mais difícil de resolver, peço ao pastor para tratar. Falo para agendar com a lider ou com o pastor. Pois eles têm mais experiência do que eu, pois eu nunca namorei. A gente ora junto, para saber se é da vontade de Deus. Os pais também têm que autorizar, mesmo se não forem evangélicos, pois Deus deu autoridade aos nossos pais. Eu aconselho meus discípulos a não namorarem por empolgação ou porque está todo mundo namorando.

A sexualidade é um tema que incita diálogos e conflitos entre os diferentes ciclos da vida e dos sujeitos. Para a vivência do agendamento da sexualidade, é demandado ao jovem fazer consultas recorrentes aos seus líderes sobre os processos e os caminhos trilhados nessa esfera cultural. Por sua vez, os jovens líderes são duplamente demandados: primeiro, para que deixem alguém cuidar de suas sexualidades e, segundo, para o cuidado das sexualidades de outros jovens. Contudo, diante da inexperiência ou da complexidade dos casos trazidos pelos jovens discípulos, eles passam aos adultos a tarefa de aconselhamento.

Nesse sentido, os jovens líderes operam como porta-vozes ou mediadores acerca de decisões a serem tomadas no relacionamento afetivo-sexual. Não se trata de um processo tranquilo, pois os jovens discípulos chegam a eles com os mais diferentes temas ou com os mesmos conflitos vividos, nem sempre sabendo como encaminhar as questões propostas. Com isso, ocorre uma espécie de cuidado compartilhado entre jovens líderes e líderes de jovens (adultos).

Os jovens líderes, enquanto são vistos como porta-vozes do programa institucional, são tidos (e muitos se veem) também como inexperientes na temática afetivo-sexual. Os adultos, ao passo que são vistos como os principais porta-vozes das interdições na sexualidade, são tidos também como mais experientes. Os adultos são reconhecidos, principalmente por aqueles jovens líderes mais comprometidos com o projeto socializador da 
igreja, como autoridades legítimas e possuidores de uma maior familiaridade com o mundo e os costumes (ARENDT, 1987) da igreja, noção que, posta em prática, visa o afinamento entre o programado e o vivido. Nesses termos, parece interessante o ensaio de Walter Benjamin, intitulado Experiência:

Travamos nossa luta por responsabilidade contra um ser mascarado. A máscara do adulto chama-se "experiência". Ela é inexpressiva, impenetrável, sempre a mesma. Esse adulto já vivenciou tudo: juventude, ideais, esperanças, mulheres. Foi tudo ilusão. Ficamos, com frequência, intimidados ou amargurados. Talvez ele tenha razão. O que podemos objetarlhe? Nós ainda não experimentamos nada. (BENJAMIM, 2005, p. 21)

As trocas simbólicas existentes no processo de socialização, longe de serem apenas espontâneas e constitutivas dos laços sociais, expressam o caráter interessado e ideológico das alianças (SETTON, 2009), revelando hierarquias e classificações entre os sujeitos. Por vezes, manifestam aquilo que são prerrogativas dos antigos ou mais experientes ou dos que possuem "mais poder e ou autoridade sobre o que se oferece ou se disponibiliza simbolicamente", ou ainda daqueles que têm em excesso e podem doar sem que lhes façam falta, "pois, ao contrário das trocas materiais, a dádiva simbólica faz circular projetos e crenças” (SETTON, 2009, p. 50).

Há jovens líderes que, no cuidado de seus discípulos, negociam diferentes programas de socialização e não se limitam ao agendamento da sexualidade proposto pela igreja. Alguns desenvolvem uma espécie de cuidado autônomo, cujo caráter é ora convergente ora divergente, o que pode implicar na perda de força simbólica ou de espaço espiritual (SETTON, 2009) da autoridade dos adultos no processo socializador e uma agregação de prestígio em relação aos discípulos.

Minha discípula começou a namorar e percebi que estava com aquele fogo todo. Esses meninos de 13, 14 anos são assim, quando começam a namorar não sabem os limites. Então, quando fui discipulá-la, eu falei para se cuidar, se valorizar, saber o lugar dela enquanto mulher. Pois se não tomar cuidado, rapidinho estará grâvida. Então, eu falei para ela se prevenir e ir à ginecologista. Falei [para usar camisinha]. Pois não adianta eu dizer para ela não fazer sexo. Ela vai fazer. Então, eu tenho que aconselhar a se prevenir. Acho que é melhor assim. Sou contra essa coisa de ficar martelando "não pode", "não pode", pois ela vai fazer. Por conta desse "não pode" é que as igrejas evangélicas são campeãs em meninas grávidas. (depoimento de um jovem líder)

Dessa maneira, no momento em que os jovens exercem o ofício de socializadores, não são porta-vozes apenas do agendamento da sexualidade eclesial, mas também de um agendamento próprio, resultado das concordâncias e discordâncias a respeito dos princípios propostos pelas diferentes instâncias sociais que influem culturalmente sobre suas 
experiências. Isso ocorre porque os jovens líderes possuem uma visão cruzada sobre o tema da sexualidade, revelando a interdependência entre as categorias de julgamento. Assim, os jovens são porta-vozes de suas próprias "boas novas", experiências, percepções e formas de ver um assunto.

Considerando as especificações das experiências dessa jovem líder, é interessante observar que ela estudou em uma escola com jovens feministas que trabalhavam, junto às estudantes, temas sobre a prevenção à gravidez, descriminalização do aborto e direitos das mulheres. Não se trata de afirmar que essa jovem possua uma vivência sexual tranquila, pois, no cotidiano, ela percebe tensões próximas às vividas por suas discípulas, uma vez que, por "fazer sexo" pré-nupcialmente se considera e é considerada dissidente no agendamento da sexualidade compartilhado, tanto pela igreja quanto por sua família. Ela tem muito clara a noção de pecado. Porém, a partir da “auto-análise" que faz da sua experiência de socialização, ela percebe que o fato de conhecer a interdição do sexo pré-nupcial não reduz o desejo de "fazer sexo". Assim, atua como mediadora com certa autonomia, cruzando "valores modernizantes" de reivindicação dos direitos das mulheres quanto à prevenção da gravidez com a preservação de "valores da igreja", contrários ao direito de escolha da mulher em relação ao aborto.

Nessa direção, Bernard Lahire $(2002,2006)$ observa uma tendência dos sujeitos a resistirem às disposições culturais programadas, pois é constante a mobilização de interesses em direções opostas e a existência de referências culturais concorrentes. Assim, os esquemas de ação da jovem pesquisada, bem como sua disposição de habitus na esfera afetivo-sexual resultam da coerência dos princípios de socialização interiorizados (BERGER, 1985) e compostos - assim como música pop, uma hibridação de referências conceituais e culturais - ao longo de sua experiência social (DUBET, 1994). Contudo, diferentemente de Lahire (2002; 2006), percebo que a pluralidade, a contradição e a heterogeneidade dos mundos sociais em que a jovem vive (família, igreja, escola e, mais recentemente, a universidade, o grupo de amigas, namoro) contribuem para que possa, simultânea e sucessivamente, organizar seu estoque de esquemas de ação ou de habitus de forma híbrida (SETTON, 2009) e dinâmica.

Outra modalidade de mediação na socialização para a sexualidade na juventude pode ser encontrada em uma espécie de auto-cuidado. Alguns jovens, tanto de gosto afetivo-sexual de mesmo sexo como de sexo oposto, optam por não colocar suas experiências sexuais no circuito de socialização 
para serem cuidados por um "outro" que não partilha das mesmas visões acerca do tema. Um dos entrevistados, jovem do sexo masculino, que gosta de menina afirmou:

Eu não[falei com o pastor que faço sexo com a (nome suprimido)]. Para que eu vou falar? Eu sei o que vou ouvir. [Também] não [me procuram para tratar do assunto]. Acho que têm medo de mim. Acham que eu sou meio grosso, não sou de ficar dando espaço para as pessoas invadirem a minha vida.

Uma jovem que gosta de menina também disse que "Não!!!!!!! Ainda não vou contar isso, né! Não quero que fiquem no meu pé. Toda hora vai ter alguém para conversar comigo. Estou me resolvendo sozinha."

Nesses casos apresentados, evidencia-se que os jovens, ocasionalmente, procuram amigos externos à igreja ou os próprios companheiros de sexo para a resolução das tensões e dos conflitos, enquanto outros tratam consigo mesmos tais questões. Cada sujeito possui uma especificação que o faz ou não confiar a sexualidade ao cuidado de outro no ambiente da igreja.

Pode-se entender, ainda, que os jovens são participantes ativos da elaboração de sua disposição afetivo-sexual. Processo que resulta do trabalho individual e coletivo, revelador de trocas simbólicas entre os sujeitos e os universos sociais vividos. Assim, a disposição afetivo-sexual é constituída numa dinâmica processual de afirmação e ou de negação da reciprocidade de conteúdos e práticas entre jovens, adultos, líderes e discípulos. As estratégias da igreja e dos jovens visam manter certo equilíbrio das relações com os outros e consigo mesmo.

Nesse sentido, as considerações de Guy Vincent (2004) são pertinentes, quando propõe o uso do verbo reflexivo socializar-se, por considerar que ele exprime um modo particular de estar, construir e relacionar-se com e no universo social. Seguindo suas pistas, percebe-se que os jovens não vivem meramente uma "produção" e “reprodução" na esfera afetivo-sexual, mas uma interiorização, produto das trocas simbólicas, um processo permanente de se fazer, refazer-se e se desfazer. A parceria com um "outro" legítimo tende a manter o circuito de socialização mais ou menos estável, reafirmando as posições de cada sujeito no processo; a autonomia no cuidado do "outro" pode ser, em si, resultado do cruzamento de referências culturais diversas; o autocuidado é uma forma de romper com os princípios de retribuição colocados no cuidado socializador-socializando, sendo de forma mais intensa seu próprio socializador ao criar seu circuito particular de socialização (relacionamentos afetivos e pornográficos; instâncias relevantes para a construção do gosto 
e dos exercícios do sexo, por exemplo). A partir desses apontamentos, é possível entender que a socialização pode se realizar, assim, de diferentes modos, incluindo dissidências e adesões, alianças ora rompidas ora reatadas pelo circuito de dádivas envolvendo a cosmologia do perdão.

\section{VÁLVULAS DE ESCAPE}

Em todas as situações em que conversei com os jovens acerca da sexualidade, independentemente da relação estabelecida com os socializadores, havia o cuidado - para alguns, um cuidado inicial, para outros, permante - de não se desviar dos princípios ensinados pelos líderes, observando sua condição de ovelha seguindo os comandos do pastor. Esse receio dos jovens resulta do próprio reconhecimento de que as dissidências são capazes de desestabilizar o circuito de trocas simbólicas, distanciando os sujeitos da comunidade de fé, afetando em maior ou menor grau a relação com o Sagrado.

Tristeza, choro, culpa são sentimentos recorrentes entre os jovens, especialmente aqueles em início de carreira sexual e religiosa. Tomados por um sentimento de vergonha por terem pecado e, mais intenso ainda, se prostituído, resultado da subjetivação de categorias de julgamento atribuídas como ensinamentos do "Poderoso Deus", mediador "onisciente, onipotente e onipresente" do processo de socialização, esforçam-se para, mesmo que por pouco tempo (alguns, por um curtíssimo tempo, um, dois dias, ou horas), experimentar e viver os princípios propostos pela igreja. Uma menina afirmou que “Quando se está fazendo(sexo), é aquela coisa, é o máximo. Mas quando termina vem aquele sentimento de culpa. Batia uma tristeza. Era aquela coisa, a gente fazia e depois chorava." Outro garoto, que gosta de menino, informou, sobre atos de transgressão que "ficava assim: hoje eu não vou pensar em homem. Mas quando eu via, eu já estava pensando. Passava alguém, ops!, já estava pensando." Outro garoto, que gosta do sexo oposto, assinalou que "todo domingo fazia um compromisso: "eu não vou me masturbar mais". Isso, no domingo, mas, na terça, já tinha caído em pecado de novo.” Daí, a importância do perdão para a reintegração dos vínculos com o Sagrado.

Percebe-se que os sujeitos da socialização não se limitam apenas aos jovens e aos líderes da fé. Deus é integrante privilegiado do processo, visto que é ele (ou a partir da noção do Sagrado) quem normatiza e classifica as ações entre "coisas da carne" e "coisas do espírito". Ele é o sujeito fonte geradora das categorias de percepção do cristão. Não por acaso, Deus é considerado análogo à figura do pai, de acordo com um modelo de família tradicional. 
Em suma, os irmãos e demais parentes podem influir sobre o processo de socialização dos filhos, mas é Deus quem autoriza, normatiza, aprova ou reprova as ações, pois segundo a orientação bíblica, “é dele, por Ele e para Ele que são todas as coisas", como consta em Romanos, capítulo 11 e versículo 36 (BÍBLIA ONLINE).

Nessa lógica de família, a igreja figura como mãe submissa àquele que é o "cabeça” da casa. Ela é responsável pelo cuidado cotidiano, atende às necessidades especiais dos filhos e orienta suas ações a partir dos princípios valorizados pelo chefe do lar. Assim, por maior que seja a afetividade entre os filhos e a mãe, nesse modelo, eles sabem a quem realmente agradam ou desagradam suas ações. Por essa razão, por maior que seja o conflito em torno da sexualidade entre os jovens e a igreja, a dimensão mais intensa desse conflito é vivida na relação com Deus.

Apesar da centralidade da "palavra de Deus", a socialização da sexualidade na igreja não se limita aos conhecimentos bíblicos, mas articula-se também com as construções sociais acerca do tema. Cada socializador constrói um tipo de conteúdo para utilizar no cuidado dos jovens. Os argumentos são, por vezes, fusões entre disposições valorizadas pela Bíblia e argumentos disponíveis nas demais instâncias sociais ou formulados a partir das próprias experiências de socialização como socializador e, simultaneamente, socializando.

No âmbito da instância socializadora familiar, alguns jovens relataram que possuem certa facilidade em conversar sobre a sexualidade com parentes, mas a maioria deles tem dificuldades em abordar o tema com familiares e adultos, visto que em muitos casos os jovens vivenciam dissidências em relação às orientações programadas pelos socializadores.

Na medida em que o diálogo possa estimular um conflito com aquele que tem maior autoridade no processo de socialização, os jovens evitam informar suas experiências dissidentes a fim de manter em equilíbrio as relações entre os sujeitos. As dificuldades para tratar dos assuntos da sexualidade na família, especialmente com pais e mães, vão desde não saber como iniciar uma conversa, passando por considerar os pais conservadores e inadequados, chegando às tentativas frustradas de discutir a questão. Perguntado se já havia tratado sobre sexo com alguém da família, um jovem menino, que gosta de menina, relatou: “Com a minha mãe. Já veio me perguntando: 'Você está fazendo sexo? Agora quer que eu seja avó? Não vou criar moleque seu, não'. Aí, não rola de conversar. Já veio me acusando. Deixei pra lá. Eu converso com meu irmão mais velho. Ele é mais cabeça. Com o líder também. 
Outro jovem, que gosta de menino disse que não conta tudo para seu líder: Claaaaaaaaaaaro que não! Conto só o que dá para contar. Não, não. [não contou para ele que fez sexo na rua, em público, com mais de um cara] Não tem clima para contar isso.

Conto mais sobre as minhas crises. Pois se contar tudo que eu já fiz, ele perde os cabelos da cabeça. Ele fica louco.

Uma pastora informou que a abordagem sobre sexualidade procura seguir de acordo com o que é exposto pelos jovens como sendo um problema: "eles nos procuram quando estão com algum desconforto ou problema. Aí, a gente acompanha, orienta, aconselha, ora junto. Tem problemas os mais diversos. Menina que termina com namorado, dúvidas sobre sexo, casamento, tudo." Segundo ela, não se pode obrigar alguém a falar ou a fazer algo que não quer: “Aí, é com ele e Deus. A gente tenta ajudar, mas só muda quem quer mudar. Eu pergunto se está tudo bem; se ele fala que está, eu não posso insistir. Eu tenho que acompanhar e respeitar o tempo de cada pessoa."

Mesmo entre aqueles jovens que conversam em família sobre sexualidade, é recorrente privilegiar outras pessoas próximas para o relato das experiências sexuais. Contudo, os jovens também não contam aos socializadores "aquilo que eles não possam aguentar"; ; revelam apenas aquilo que julgam possível para o diálogo e a manutenção do equilíbrio das interações. Há uma correspondência de estratégias no conteúdo da comunicação entre eles. Os socializadores desafiam os jovens a viverem nos marcos do programa institucional de socialização; por sua vez, os jovens desafiam os socializadores a compreenderem suas dissidências sem desequilibrarem as interações. Assim, se os socializadores desafiam os jovens apenas naquilo em que os discípulos podem "aguentar", os socializandos contam apenas aquilo que os socializadores podem "aguentar".

Os jovens, na busca de cuidado e conforto junto aos socializadores, não revelam a eles o detalhamento das experiências geradoras de grande estranhamento, como, por exemplo, lugares menos convencionais que uma casa, quarto e cama em que uma pessoa possa fazer sexo com a outra. Fica para o socializador (em maior grau, adultos e jovens que não tiveram uma sociabilidade não-evangélica ou uma sexualidade dissidente) a ideia de que o jovem somente se relaciona sexualmente com pessoas do mesmo sexo se for às "baladas" não-evangélicas ou se for à Parada do Orgulho Gay ou andar em companhia de outros dissidentes. Dessa forma, as práticas sexuais em um banheiro público, por exemplo, não são reveladas ao socializador, pois, de modo homólogo, trata-se de um desafio que se pode não “aguentar”.

Os socializadores enfatizaram que desafiam os jovens a todo o tempo; contudo, não com "aquilo que [os jovens] não possam aguentar". Nesse caso, parece que a recíproca é verdadeira. 
Portanto, essa homologia entre posições do jovens socializandos e dos socializadores se caracteriza pela não literalidade das informações passadas, visto que ambos os lados teriam dificuldade em compreendê-las e o processo de estranhamento entre socializador e socializando seria ainda maior. Assim, muitos jovens informantes compartilham o cuidado de suas sexualidades com outras pessoas; em vez de compactuar com os socializadores da igreja, valorizam outros amigos que possam olhar com menor estranhamento para as suas experiências. Privilegiam amigos não-evangélicos que vivenciam as mesmas condições, cuidando para que suas dissidências em relação ao programa da igreja não impeçam a conversão deles.

Nessa busca de conforto e respostas para os conflitos em torno do sexo, aqueles que desejam viver na dissidência e ao mesmo tempo compartilhar os outros símbolos sagrados da igreja se inserem parcialmente no circuito de dádivas, contando parcialmente suas vivências ou se inserindo nele. Desses, há os que buscam construir estratégias de contra-argumentação visando atenuar seus conflitos.

O processo de agendamento da sexualidade da igreja não inclui estímulos ao uso de preservativos para evitar as doenças sexualmente transmissíveis (DST's) e a gravidez, visto que não se planeja que os jovens exercitem o sexo com parceiros antes do casamento. Todos têm consciência dos chamados "efeitos perversos" atribuídos ao exercício do sexo ("gravidez indesejada", DST`s, envolvimentos afetivos geradores de conflitos, casamento sem amor). Assim, por mais que a dissidência afetivo-sexual tensione as interações entre socializadores e socializandos, por mais que exista um conflito do sujeito consigo mesmo, por ter subjetivado a interdição como uma ordenança do Sagrado, a ideia de que usam o preservativo ou exercitam o sexo com a pessoa com a qual pretendem se casar não atenua os conflitos com a igreja ou com Deus, mas atenua a relação tensa do sujeito consigo mesmo. Alguns depoimentos que corroboram essa percepção: “Mas o que eu ficava pensando era assim: 'Estou fazendo sexo com meu namorado, a gente se previne. Por que não pode?"” "Eu faço sexo com minha namorada; não posso, mas faço, sou homem. Faz parte. Eu vou casar com ela.”

Por outro lado, aqueles que possuem gosto afetivo-sexual por pessoas do mesmo sexo não conseguem atenuar todos os seus conflitos. Relata um jovem que gosta de menino: "Eu faço sexo com camisinha, isso me deixa mais tranquilo, mas a questão não é essa, mas com quem eu estou fazendo. Esse é o problema”. Uma parte dos conflitos é atenuada pelo uso de preservativos, 
mas, como o sexo é exercitado com pessoas do mesmo sexo, com as quais está interditado estabelecer o vínculo conjugal, a outra parte não é atenuada, pois a dissidência, nesse caso, é tida como um duplo desvio.

Em suma, o jovem sabe reconhecer a dissidência em sua conduta, não apenas pela interiorização da cosmologia “carne" e "espírito" ensinada pela igreja, muito significativa e estimuladora de conflitos profundos, mas, sobretudo, porque agrega-se aos seus conflitos o fato de outras instâncias sociais também utilizarem classificações dualistas das experiências sociais no âmbito da sexualidade. Assim, o jovem dissidente busca num "outro", estranho à sua fé, mas familiar à sua dissidência, esclarecimentos sobre sua experiência social a fim de poder, consigo mesmo, familiarizar-se com a dissidência e tentar articulá-la à sua experiência de fé.

Assim, os sujeitos munidos de informações adquiridas em diferentes instâncias sociais contra-argumentam na tentativa de construir outras estruturas compreensivas para suas disposições de habitus. Prontamente, a igreja e seus líderes informam que não existe distinção de valores entre os pecados. Com isso, observa-se que todos os jovens buscam construir suas válvulas de escape na sexualidade. Porém, a constituição da válvula de escape é sempre mais complexa em se tratando dos que se desviam do gosto de sexo oposto, dada a hierarquização, não declarada, mas efetivada e sentida do que é "pecadinho" e do que é “pecadão", impondo aos dissidentes modulares mais vergonha, culpa e sofrimento.

\section{CONSIDERAÇÕES FINAIS}

A socialização da juventude para a sexualidade ocorre por meio da interação social e do contato cultural entre diferentes instâncias e sujeitos. Analisada a partir da noção de fato social total (MAUSS, 2003) e socialização como um fato social total (SETTON, 2009), observam-se as trocas simbólicas e o contexto em que essas trocas ocorrem, bem como os significados atribuídos ao que é trocado. Por meio da observação desses sistemas de trocas interdependentes, confluentes e divergentes, entre instâncias e sujeitos, torna-se possível compreender parte das estratégias e tensões existentes.

$\mathrm{Na}$ igreja, polarizam-se carne e espírito; oferecem-se soluções para sentimentos de culpa a partir da lógica do perdão; enfatizam-se as renúncias como retribuição ao Sagrado. Com isso, buscam-se normatizar e indicar as fronteiras e os limites das experiências sociais na esfera da sexualidade, 
tentando dizer ao jovem que nem tudo pode ser "festa". Em outros termos, não é possível suspender a realidade e os valores da igreja em todas as áreas da vida. Aponta-se a "necessidade" de controle social sobre a sexualidade juvenil, apostando em um diálogo orientado e uma negociação dentro dos limites que favorecem a adesão de mais fiéis, sem haveruma descaracterização da mensagem central da igreja.

Concluindo, é possível afirmar que os jovens possuem uma visão cruzada dos acontecimentos sociais, resultado de suas reflexividades que se operam nas práticas de adesão e dissidência, em que alguns conseguem contribuir para a revitalização, mesmo que lenta, do sistema de simbolização. Assim, a tentativa de controlar docilmente os jovens, por vezes, é abalada pelo fato de que eles também controlam docilmente seus processos de socialização, ou seja, são ao mesmo tempo controlados e controladores. 


\section{The interweavings of socialization: a socio- anthropological analysis of youth sexuality in religion}

Abstract: This paper seeks to contribute to a reflection on diversity and unity in positions taken on education and sexuality within an evangelical group in Brazil. This is the result of an ethnography done with a Neo-Pentecostal evangelical church. The ways in which the church and the subjects (adults and youth) built the processes of dialog, negotiation and control in regards to sexuality were investigated. From the perspective of Education Sociology, claims and counterclaims, strategies and cosmologies were looked at in relation to adhering to or remaining separate from a sexual grouping. The conclusion reached is that these young people experience socialization in terms of sexuality between practices of adhesion or disagreement and that the church's attempt to control them, through advisers whose strategy is not to go beyond the limit of what their followers could withstand, could be shaken by the fact that, on the other hand, these young people only talk to their advisors about matters that would not cause too much tension.

Keywords: Socialization. Religion. Sexuality.Youth. 


\section{REFERÊNCIAS}

ARENDT, H. A condição humana. Rio de Janeiro: Forense-Universitária, 1987.

BENEDICT, R. 0 crisântemo e a espada: padrões da cultura japonesa. São Paulo: Perspectiva, 1972.

BENJAMIN, W. Reflexões: a criança, o brinquedo, a educação. São Paulo: Duas Cidades; Editora 34, 2005.

BERGER, P. O dossel sagrado: elementos para uma teoria sociológica da religião. São Paulo: Paulus, 1985.

BÍBLIA ONLINE. Disponível em: http://www.bibliaonline.com.br. Acesso entre 2007 e 2010.

BOURDIEU, P. Razões práticas: sobre a teoria da ação. Campinas: Papirus Editora, 1996.

. Questões de sociologia. Lisboa: Fim de Século, 2003.

. A distinção: crítica social do julgamento. Porto Alegre: Zouk, 2008.

DUARTE, L. F. D.Ethos privado e justificação religiosa. Negociações da reprodução na sociedade brasileira. In. HEILBORN, M. L. et al. (Orgs.). Sexualidade, Família e Ethos Religioso. Rio de Janeiro: Garamond, 2005.

DUBET, F. Sociologia da experiência. Lisboa: Instituto Piaget, 1994.

FOUCAULT, M. História da Sexualidade I: a vontade de saber. Rio de Janeiro: Edições Graal, 1988.

GARCÍA-CANCLINI, N. Culturas híbridas: estratégias para entrar e sair da modernidade. São Paulo: Edusp, 2008.

GIDDENS, A. As consequências da modernidade. São Paulo: Unesp, 1991.

GOMES, E. E. Ensaios etnográficos sobre a socialização da juventude para a sexualidade e a fé: “vem, você vai gostar!". Dissertação (Mestrado em Educação) - Faculdade de Educação da Universidade de São Paulo, 2010.

LAHIRE, B. Homem plural: os determinantes da ação. Petrópolis: Vozes, 2002. LAHIRE, B. A cultura dos indivíduos. Porto Alegre: ARTMED, 2006. 
LÉVI-STRAUSS, C. Introdução à obra de Marcel Mauss. In. MAUSS, Marcel. Sociologia e antropologia. São Paulo: Cosac Naify, 2003.

MAUSS, M. Sociologia e antropologia. São Paulo: Cosac Naify, 2003.

SETTON, M. da G. J. A teoria do habitus em Pierre Bourdieu: uma leitura contemporânea. Revista Brasileira de Educação, n.20, mai./jun/jul/ago, p. 60-70, 2002.

A socialização como fato social total: um ensaio sobre a teoria do habitus. Tese de livre docência. Universidade de São Paulo, São Paulo, 2009.

VINCENT, G. Recherchessur la Socialisation Démocratique. Lyon: Presses Universitaires de Lyon, 2004.

RECEBIDO: Novembro de 2012.

APROVADO: Março de 2013. 